\title{
DINÂMICAS TERRITORIAIS E DESENVOLVIMENTO BRASILEIRO EM QUESTÃO'
}

\author{
Eliane Tomiasi PAULINO²
}

\begin{abstract}
RESUMO
O objetivo do texto é refletir sobre as dinâmicas territoriais em curso no Brasil a partir de um diálogo capaz de iluminar a problemática da colonialidade desde a América Latina, região onde a concentração da terra e da riqueza é a maior do planeta, tanto quanto a violência que é, dialeticamente, resultado das desigualdades sociais. Para compreendê-las, parte-se do conceito que orienta os debates sobre o devir dentro e fora da academia: o desenvolvimento. Desnudar sua polissemia, expressa na confusão com crescimento econômico, impõe a necessidade de correlações com as contradições de classes e com a alienação sustentada pela ideologia. No plano das representações, pode-se perceber como a expressão é esvaziada do rigor conceitual que lhe corresponde, reaparecendo como estratégia para a criminalização radical das lutas contra hegemônicas, canalizando a polarização que se traduz numa marcha persecutória contra todos com eventual poder de expor o consenso demolidor do Estado de Direito. A progressão do obscurantismo alicerçado no manejo competente da engenharia linguística é posicionada no contexto de algumas dinâmicas donde conclui-se que a voracidade de classe na apropriação dos ativos e na socialização dos passivos territoriais aponta para um impasse civilizacional sem precedentes, particularmente no Brasil.
\end{abstract}

Palavras-chave: Neoextrativismo. Latifúndio. Voracidade. Autodeclaração fraudulenta. Ativos e passivos territoriais.

\section{TERRITORIAL DYNAMICS AND BRAZILIAN DEVELOPMENT IN QUESTION}

\begin{abstract}
The aim of the text is to reflect on the undergoing territorial dynamics in Brazil with a dialogue capable to set light upon the problematic of coloniality of power from Latin America, a region with the largest concentration of land and wealth on the planet, as well as violence, which is, dialectically, the result of unparalleled social differences. In order to understand them, we start from the concept that guides debates on the philosophical becoming inside and outside academia: development. Denuding its polysemy - expressed in confusion with economic growth -, imposes a necessity of correlations with class contradictions and alienation sustained by ideology. Within the framework of representations,

\footnotetext{
${ }^{1}$ Texto apresentado em palestra realizada no II Congresso Brasileiro de Organização do Espaço e XIV Seminário do Programa de Pós-Graduação (II CBOE), realizado na cidade de Rio Claro/SP, entre os dias 24 a 28 de março de 2019, intitulado "Soberania e Ciência no século XXI: a decolonialidade do saber como novo paradigma geografia?".

2 Professora do Programa de Pós-Graduação em Geografia - Universidade Estadual de Londrina.
} 
one may notice how expression is emptied of its conceptual content, reappearing as a strategy for the radical criminalization of counter-hegemonic struggles, channeling a polarization that translates into a persecutory march against all those potentially able to expose the demolishing consensus set by the Rule of Law. The progression of obscurantism based on a competent management of linguistic engineering is positioned in the context of some dynamics whereby one concludes that the class voracity in seizing assets and socializing territorial liabilities points to an unprecedented civilization deadlock, particularly in Brazil.

Kaywords: Neoextractivism. Latifundio. Voracity. Fraudulent self-declaration. Territorial assets and liabilities.

\section{DINÁMICAS TERRITORIALES Y DESARROLLO BRASILEÑO EN CUESTIÓN}

\section{RESUMEN}

El objetivo del texto es reflexionar sobre las dinámicas territoriales en curso en Brasil a partir de un diálogo capaz de iluminar la problemática de la "colonialidad" desde América Latina, región donde la concentración de las tierras y de la riqueza es la mayor del planeta, tanto cuanto la violencia que es, dialécticamente, resultado de las desigualdades sociales sin paralelo. Para comprenderlas, se parte del concepto que orienta los debates sobre el devenir dentro y fuera de la academia: el desarrollo. Desnudar su polisemia, expresada en la confusión con el crecimiento económico, impone la necesidad de correlacionarla con las contradicciones de clases y con la alienación sustentada por la ideología. En el plano de las representaciones, se puede ver como la expresión está vacía del contenido conceptual que le corresponde, reapareciendo como estrategia para la criminalización radical de las lcontra hegemonías, canalizando la polarización que se traduce en una marcha persecutoria contra todos los que tengan un eventual poder de exponer el consenso demoledor del Estado de Derecho. La progresión del oscurantismo basado en el manejo competente de la ingeniería lingüística se ubica en el contexto de algunas dinámicas donde se concluye que la voracidad de clases en la apropiación de los activos y en la socialización de los pasivos territoriales señala un impasse civilizatorio sin precedentes, particularmente en Brasil.

Palabras clave: Neoextractivismo. Latifundia. Voracidad. Autodeclaración fraudulenta. Activos y pasivos territoriales.

\section{INTRODUÇÃO}

Como parte das atividades do II Congresso Brasileiro de Organização do Espaço e da tarefa proposta para a mesa: $O$ desenvolvimento brasileiro em questão: mutações, dicotomias e dinâmicas territoriais, o propósito desse 
ensaio é analisar a problemática estabelecida desde uma questão central, o desenvolvimento. Sua amplitude, complexidade e diferentes possibilidades de entendimento exigem alguns recortes, sendo oportuno indicar, de antemão, que é desde a proposta da decolonialidade do saber que o elaboramos.

Isso é o que nos motiva à problematização conceitual a partir de duas perspectivas: a conjuntural e a estrutural, razão pela qual diferentes escalas se entrecuzam e são colocadas em diálogo, buscando-se perscrutar as fronteiras do pensar e agir desde o lugar das classes.

Nestes tempos em que a bajulação e a verborragia inepta transita dos palanques às altas tribunas, refletir sobre os fundamentos da colonialidade é uma forma de evidenciar, para superar, aquilo que fere a soberania e apequena o horizonte.

Para começar, faz-se necessário explicitar a questão do método subjacente ao texto. Sabendo-se que não existe verdade objetiva no sentido da ontologia do objeto, parte-se da premissa de que sociedade e natureza, os dois elementos que permitem quantificar e qualificar o desenvolvimento, tema em tela, são indivisíveis.

A escolha de um viés em que a propriedade privada da terra aparece como estrutural à análise se justifica pois, como ensinara Polanyi (1980, p. 84), terra é o outro nome dado à natureza. Em suas palavras, "o trabalho e a terra nada mais são do que os próprios seres humanos nos quais consistem todas as sociedades e o ambiente natural no qual elas existem".

Por isso, parte-se de um arcabouço teórico orientado para a compreensão da problemática agrária como um dos fundamentos do processo de acumulação em nome do desenvolvimento, evocando-se as contradições de classe do capitalismo para compreendê-lo.

A metodologia está apoiada em Correa (2003), observando-se seus apontamentos para o estabelecimento do recorte espacial e temporal, desde a problemática dada. A articulação entre essas dimensões é apresentada segundo uma proposição de escala que não é só cartográfica, mas também conceitual. Define-se assim o Sistema Mundo como escala do geral, a América Latina como escala do particular e o Brasil como escala do singular. 
Em que pese o risco de estranhamento, optou-se pelo conceito de latifúndio em vista de sua perfeita aderência à realidade. Malgrado a sua proscrição da narrativa legal expressa no ordenamento jurídico posterior ao Estatuto da Terra, depreende-se que a dissimulação operada pela eliminação da palavra é um desses atos políticos que somente a ideologia de classes pode explicar.

Entretanto, as manobras linguísticas não o tornaram inimputável perante a Constituição, porque a função social está entre os condicionantes do direito de propriedade. Exatamente por isso, esse princípio atualmente está ameaçado de supressão por iniciativa de senadores da república.

Como nenhum conceito é inocente, há igual preocupação com a sinonímia entre crescimento e desenvolvimento, sobretudo pela necessidade de problematizar as artimanhas ideológicas com forte acolhida pela classe média recém constituída. Sua conduta aporofóbica 3 denuncia um enfileiramento explícito com as classes proprietárias, culminando na intolerância nunca dantes explicitada em tamanha magnitude.

Fiel à assertiva de Marx (1974), de que toda riqueza provém da mobilização entre dois elementos, terra e trabalho, toma-se a primeira como ativo territorial de primeira grandeza, correlacionando a propriedade fundiária aos processos de acumulação traduzidos no acirramento das desigualdades e de toda forma de violência que daí emana. Nesse sentido, procura-se evidenciar como tem se dado a recomposição de forças para bloquear a aplicação dos instrumentos legais contrários ao latifúndio.

Por fim, são analisadas como as medidas mais recentes do Estado, tomado na conjugação dos poderes executivo, legislativo e judiciário, expressam o governo do e para o latifúndio em prejuízo do ainda presumido Estado de Direito no Brasil.

3 Conceito cunhado por Adela Cortina (2017) para evidenciar a repulsa aos pobres e que, segundo a autora, é o que está na raiz do racismo, da xenofobia e demais manifestações de intolerância contemporânea. 


\section{AS BASES AGRÁrias dOS ARCAÍSMOS EMERGENTES NA AMÉRICA LATINA}

Os centros de poder do Sistema Mundo podem ser caracterizados pelo que se denomina dispersão concentrada, emanando daí a ordem que conforma as possibilidades, e representações, do que vem a ser o desenvolvimento onde quer que seja. Por sua vez, seu conteúdo possui alcance planetário, materializando-se no pensar e ser hegemônico do modo capitalista de produção.

Mas para não incorrer no risco de generalizações que pouco tem a acrescentar à Ciência Geográfica, é preciso escapar das teses a-espaciais e, nesse sentido, é por demais oportuno posicionar a América Latina na escala do particular, metodologicamente falando, pois se distingue no Sistema Mundo pela condição peculiar no que diz respeito à divisão internacional do trabalho.

Há na região uma inabalável unidade constitutiva de caráter geopolítico: o fornecimento de matérias primas para o mercado global, e isso não se faz sem o rígido controle sobre a terra. Na figura 1 está indicada a proporção de área ocupada pelas propriedades pequenas ${ }^{4}$, as quais constituem a maioria das unidades agrícolas dentre os países selecionados mas, que no conjunto, ocupam mínima fração territorial.

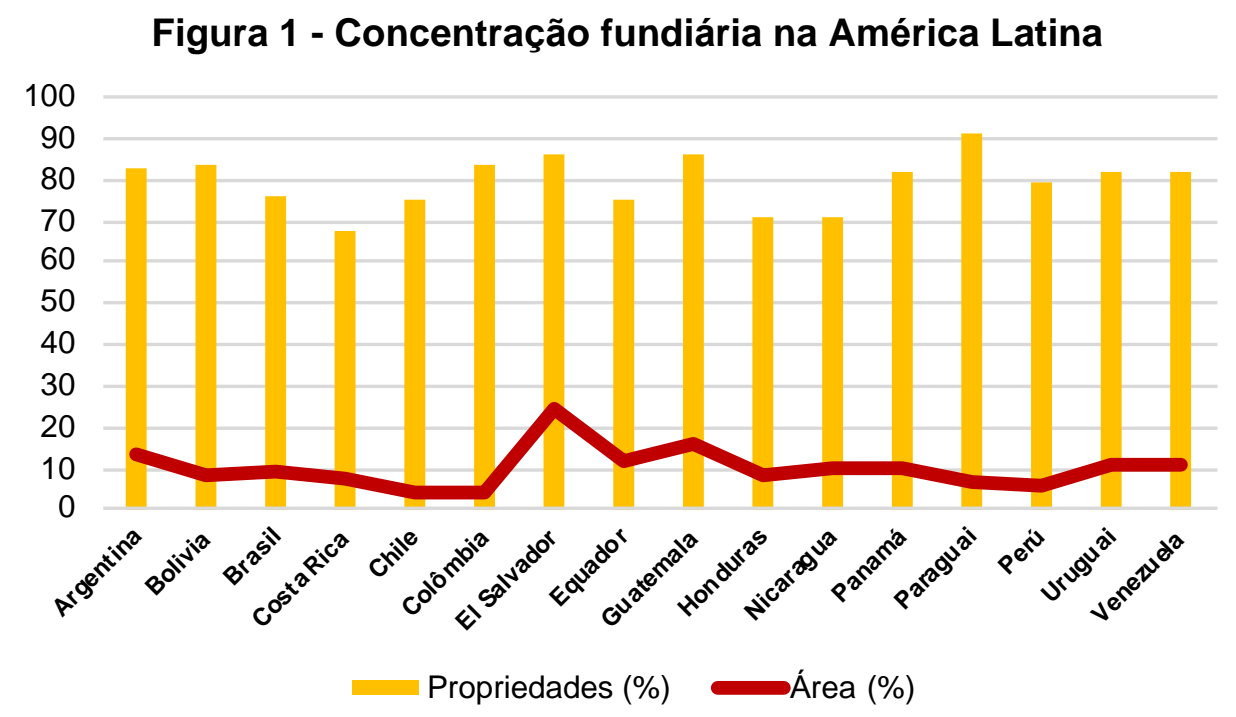

Fonte: INCRA, 2014; OXFAM, 2016.

4 No caso do Brasil, foram utilizados os dados do cadastro de imóveis. 
A figura fala por si, mas não custa lembrar que a América Latina é a região do planeta com maiores índices de concentração fundiária e o Índice de Gini o confirma: alcança 0,85 na América do Sul e 0,75 na América Central. Na África, por exemplo, o índice é de 0,56, na Europa é de 0,57 e na Ásia é de 0,55. Como consequência disso, a concentração da riqueza medida pelo Índice de Gini também é a maior do planeta, chegando a o,48. Tal índice supera inclusive o da África Subsariana, que é de 0,43, enquanto no Leste da Ásia e na América do Norte é de 0,37 (OXFAM, 2016, p. 21).

Concentração fundiária e pobreza são um par indissociável, pois a monopolização do solo é condição primaz para a degradação dos termos de troca entre proprietários e vendedores de força de trabalho. É a conjunção desses dois fatores que viabiliza o modelo extrativo depauperador que expele a maioria dos circuitos de inclusão cidadã, aqui entendidos como os que asseguram minimamente acesso aos mínimos vitais. As condições de ímpar competitividade dessa região repousam, portanto, na abundância das matérias primas assim constituídas pelo trabalho barato que converte bens ambientais em recursos naturais.

Vivemos na América Latina o tempo em que as populações foram incorporadas ao processo produtivo no passado, mas predadas, não incorporadas no processo político. Diversamente dos EUA, não houve a construção de um projeto em que houvesse um lugar igualitário para todos. (MARTINS, 2011, p. 37).

São as especificidades próprias a cada um dos países do bloco que convidam ao diálogo com a escala do singular, nesse caso, o Brasil. Se há algo que lhe confere feições sui generis é, fundamentalmente, a extensão territorial. Esse argumento objetivo tem sido útil à investidura geopolítica que, em regra, tem sido empregada para a reprodução subalterna da ordem hegemônica no Cone Sul.

É certo que a grande extensão continental foi obra de vicissitudes nos primórdios da colonização, como o insucesso na busca de metais preciosos na primeira investida exploratória. Ante a ausência da rara mercadoria, a saída para a viabilização da empresa colonial foi a agricultura tropical articulada ao tráfico humano. 
O fato é que a economia agroexportadora interessava aqui e alhures, pois criava também as condições para a defesa do território conquistado. Solução das melhores para a coroa portuguesa, sem capital e estrutura para a vigilância e controle de uma colônia distante e extraordinariamente grande, considerando as dimensões do reino5.

Sobre conveniências factuais combinadas ao critério nobiliárquico de linhagem e fidalguia disseminou-se a lógica patrimonialista, predatória e excludente tecida sobre o monopólio da terra e a escravidão. Estavam dadas as condições primárias à proeminência secular do latifúndio, desde então manejadas com a precisão necessária à sua perpetuação.

Certamente não se concebe o latifúndio enquanto instituição inabalável, do mesmo modo como refuta-se a tese de que a evolução dos processos produtivos em termos técnicos teria sido suficientemente ampla para provocar sua conversão em empresa agrícola moderna. Contrariamente, verifica-se como a história brasileira é a da vitalidade do passado a cada movimento que o renega.

Desde a instauração da república que, aliás, foi uma resposta de classe ao fim da escravidão, outro abalo às suas bases viria do consenso em torno da necessidade da reforma agrária, forjado pelas lutas camponesas da primeira metade do século passado. Mais uma vez, o escudo para a classe proprietária estaria no aparelho de Estado, dessa vez pelas armas que lançariam o país no regime de exceção por 21 anos.

Nesse período, o fortalecimento da aliança entre terra e capital se deu em meio a inexistência de direitos e garantias individuais, pois num ambiente democrático não haveria margem para que termos extorsivos ao patrimônio público e ao bem comum pudessem ser celebrados.

Um importante aliado do regime militar foi a política de subsídios fiscais, que combinava renúncia tributária incidente sobre empreendimentos urbano industriais com obrigatoriedade em implantar projetos agropecuários. Recursos monetários e amplas extensões florestadas na Amazônia foram destacados do patrimônio da união, tendo se convertido em domínio privado. Na era do "terra

$5 \mathrm{O}$ território brasileiro é aproximadamente 92 vezes maior que o de Portugal. 
sem homens para homens sem terra" forjou-se o discurso de que era necessário ocupar a Amazônia para protegê-la.

Meio século depois, a história se repetiria. A motivação da ocasião é mais uma vez a cantilena do desenvolvimento. Em nome da segurança nacional, da proteção da floresta, do progresso, do bem-estar indígena entre outras pérolas, o militar no mais alto posto da república, juntamente com um staff saído dos batalhões, proclama a decisão de paralisar a demarcação das terras indígenas e rever as que já estão demarcadas.

Nem o constrangimento constitucional detém defensores da pátria onde não há lugar para todos. "Pouco índio para muita terra" volta como mantra para o banquete dos grandes invasores desmatadores incendiários que proclamam a redenção da economia enquanto dividem os despojos nos bastidores da guerra ideológica ${ }^{6}$.

Enquanto isso, está sendo preparada a Medida Provisória da Autodeclaração como critério para obtenção do título de propriedade7 (SPAROVEK et al, 2019). Trata-se de ato derradeiro em favor da fraude e do esbulho possessório das terras da União distribuídas em Unidades de Conservação, Territórios Indígenas e Quilombolas e posses campesinas que já entraram para a contabilidade privada sem ônus para os avizinhados do aparelhado Estado brasileiro.

O fato é que os grileiros já vinham pavimentando o caminho para tanto e os dados o comprovam. No Brasil, existem dois órgãos que gerenciam informações oficiais sobre as propriedades rurais, o INCRA e o IBGE, sem que haja controle da veracidade das informações que, em ambos os casos, dependem da honestidade dos declarantes. A isso se denomina autodeclaração.

No caso do IBGE, o Censo Agropecuário se faz mediante visitas dos recenseadores em todos os estabelecimentos do país com o objetivo de diagnosticar como, onde, quanto e quem produz no campo. É no sentido de unidade produtiva, e não de propriedade da terra, que os estabelecimentos são

\footnotetext{
${ }^{6}$ Em 2019, a taxa de desmatamento estimada pelo PRODES/INPE somente para a Amazônia Legal foi de 976.200 hectares.

$7 \mathrm{O}$ anúncio foi feito pelo titular da Secretaria Especial de Assuntos Fundiários do Ministério da Agricultura em 01/10/2019. A expectativa do governo é conceder o título de propriedade definitivo a 93\% dos ocupantes ilegais de terra ainda em 2019.
} 
contabilizados. Mas em regra, o detentor da propriedade é também o empreendedor rural, sendo pouco expressivos os empreendimentos em terras arrendadas ou cedidas.

Por sua vez, o INCRA opera com a categoria imóvel, que supõe a propriedade da terra. As informações são coletadas virtualmente, por meio do Sistema Nacional de Cadastro dos Imóveis Rurais, o qual deve ser alimentado pelos declarantes, como forma de obterem o Certificado de Cadastro de Imóvel Rural (CCIR). Embora este certificado não se preste à comprovação de propriedade, é obrigatório para operações de compra e venda, bem como para acesso ao crédito agrícola. $\mathrm{O}$ problema é que, indiretamente, autentica o domínio, mesmo que o declarante não seja proprietário da área que afirma lhe pertencer.

Conforme os dois últimos Censos Agropecuários (2006, 2017), o campo brasileiro pouco se alterou, aliás apenas $40 \%$ do território brasileiro foi declarado como área privativa. Paradoxalmente, quase no mesmo período, a área certificada como propriedade privada pelo INCRA quase duplicou, conforme evidencia a figura 2, a seguir.

\section{Figura 2 - Extensão da fraude na apropriação da terra segundo o sistema de autodeclaração no Brasil}

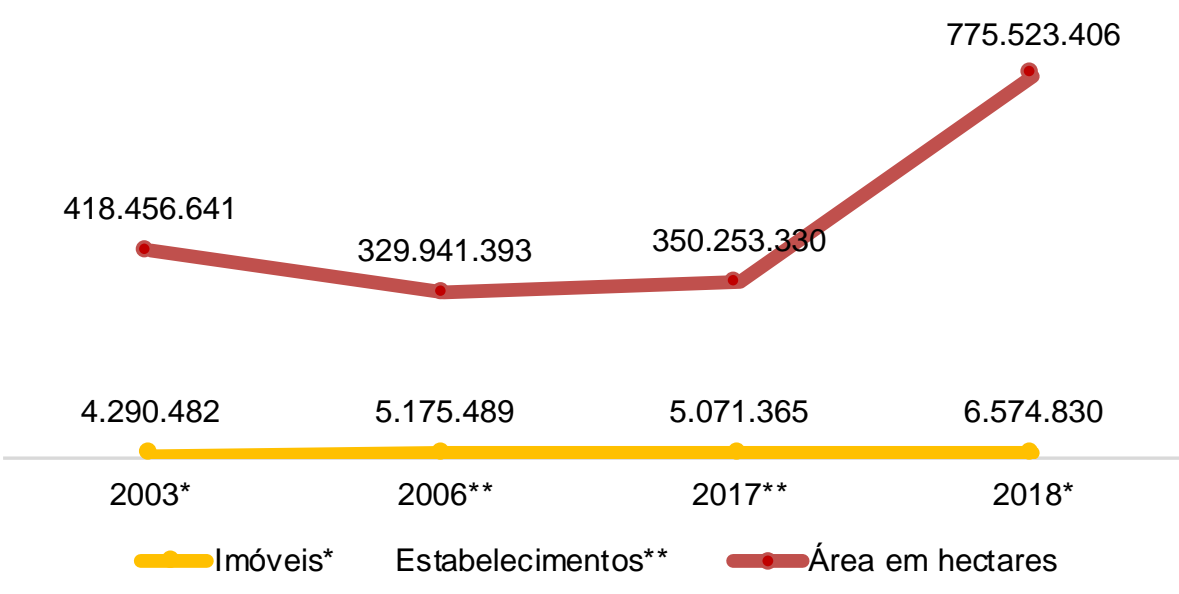

Fonte: *INCRA (2019); **IBGE (2018); Paulino (2017, p. 139).

Não resta dúvida que a diferença entre a área identificada pelos recenseadores nos trabalhos a campo e o aumento exponencial dos domínios 
certificados como privados, com aumento do tamanho médio dos imóveis, envolve uma fraude declaratória de grande magnitude. Do mesmo modo que a explosão das queimadas em 2019 se deve à presumida aquiescência do governo, pela criminalização de servidores, órgãos, dados e leis, supõe-se que o fundamento da fraude declaratória é a pretensão orientada para a legalização das falcatruas dominiais já consumadas ou por consumar o quanto antes.

A inconsistência no sistema de autodeclaração de propriedade é de tal ordem que a área dos imóveis já certificados caminha para a extrapolação das dimensões do território brasileiro passível de certificação. Sem qualquer juízo de valor, trata-se de grave atentado contra a segurança jurídica no campo.

Não esqueçamos que essa expressão é corriqueira entre proprietários pretensamente ameaçados pelos indígenas, sem terra, legislação ambiental, legislação trabalhista e assim por diante. Nem todos são grileiros, havendo proprietários de fato e de direito, cujos domínios possuem lastro incontestável no regramento legal ainda em vigor. De uma forma ou de outra, está em curso a liquidação literal do país, porque os pretensos proprietários, uma vez certificados, podem exigir os bônus do direito de propriedade. Isso recairá sobre a sociedade de um modo geral.

A propriedade fundiária é apenas uma relação que permite captar valores criados pelo trabalho que, de outra maneira, seriam reencontrados na formação na taxa média de lucro. A renda não pode criar valores, ela pode apenas transferi-los, em todos os casos, de uma classe para outra. (AMIN; VERGOPOULOS, 1986, p. 58).

O subdimensionamento territorial no sistema IBGE e o superdimensionamento no sistema INCRA impedem apontamentos precisos sobre a área transferível para quem proprietário não é, caso prospere o ato legalizador via Medida Provisória. Aqui, o tamanho do crime de lesa pátria foi dimensionado por aproximação, apurando-se a diferença contábil entre os dois sistemas de dados.

A diferença entre tudo o que foi indicado como superfície sob domínio privado no Censo Agropecuário realizado pelo IBGE em 2017 e a área declarada dos imóveis rurais certificados pelo INCRA em 2018 é de 425.270.076 hectares. Isso corresponde a metade do Brasil ou, se preferirmos, ao território de nada 
menos que a soma dos 22 maiores países da Europa, conforme representa a figura 3 , a seguir.

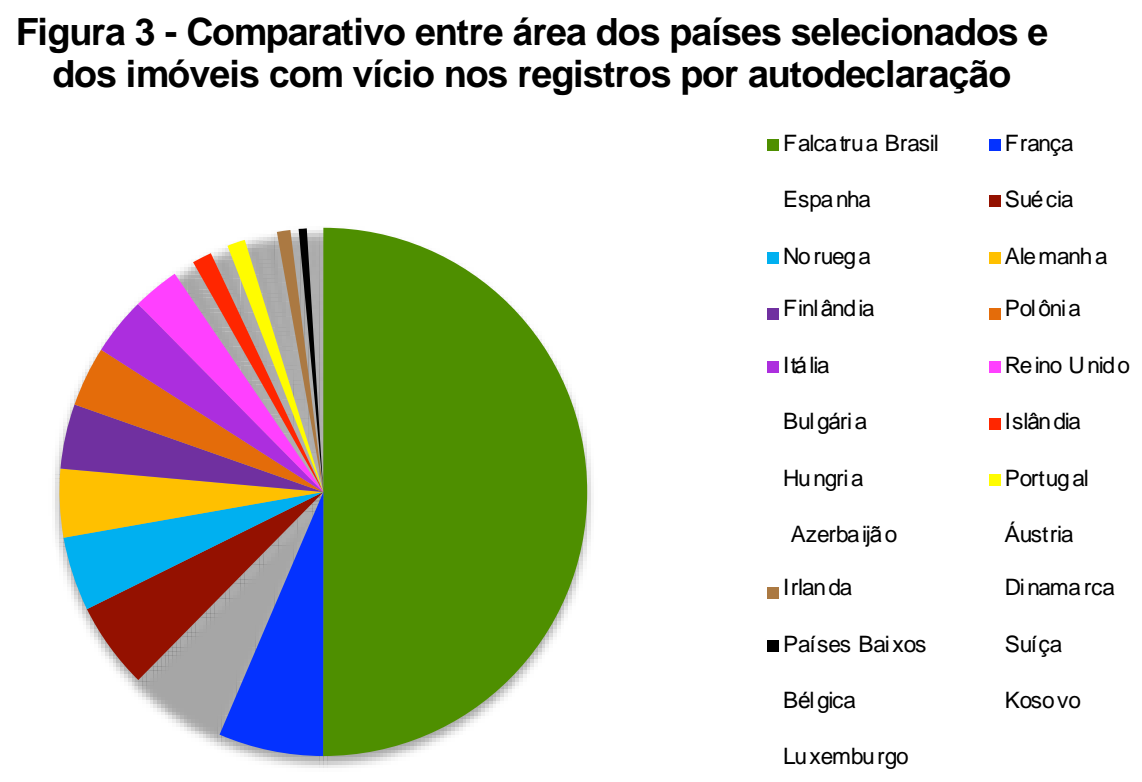

Fonte: IBGE (2018); INCRA (2019).

Por enquanto, uma parte desse meio Brasil acometido pela falsidade certificada está onerando a sociedade pela exploração/dilapidação da terra pública e das riquezas que nela há, pelos financiamentos agrícolas a juros subsidiados e outros penduricalhos menores. Conforme salientado, o certificado do INCRA não confere direito de propriedade, mas a MP da Autodeclaração o fará, caso seja referendada em meio ao vácuo de coerência pública dentre os poderes constituídos.

Restará, se assim for, o problema da obrigação constitucional que recai sobre a grande propriedade, sob pena de desapropriação: o cumprimento da função social. Mas não é exatamente produzir, cumprir legislação ambiental e trabalhista o objetivo dos grandes invasores.

Nada que uma mudança na Constituição não possa resolver. Está em curso a Proposta de Emenda Constitucional 80/2019. Segundo o filho do presidente da república e também seu autor, o objetivo da PEC é “diminuir a discricionariedade do Poder Público na avaliação de desapropriação da 
propriedade privada, tendo em vista que é um bem sagrado e deve ser protegida (sic) de injustiças". 8

Tais atos em torno da apropriação criminosa da terra sinalizam para a retomada das rédeas do Brasil pela lógica do latifúndio e todo o retrocesso que isso impõe. Não obstante, é importante lembrar que isso não perturbará os mecanismos de acumulação ampliada do capital, pois como ensinou Marx (1974), esse é um modo de produção de mais valia, cuja realização requer produção, circulação e consumo de mercadorias. Eis a imprescindibilidade da terra.

Nenhum processo produtivo se exerce no vazio; utiliza sempre as forças da natureza: o vento que faz girar o moinho, as forças biológicas que fazem brotar as plantas [...]. Enfim, quase toda atividade econômica não deixa de possuir um substrato geográfico, de localização necessária [...]. A questão é saber quais as condições sociais que regulam o acesso à utilização dessas forças. (AMIN; VERGOPOULOS, 1986, p. 14).

Em admitindo-se que a renda fundiária se traduz objetivamente em retenção de uma fração do saldo monetário proveniente do trabalho depositado sobre todo e qualquer elemento da biosfera com lastro na superfície, vislumbra-se o porquê da fúria açambarcadora sobre a superfície que porventura ainda possa estar a salvo da apropriação capitalista. Não significa dizer que estão despovoados ou fora do circuito mercantil, apenas fora do circuito de produção e realização da mais valia diretamente.

A propriedade privada da terra exerce uma função essencial ao
desenvolvimento do capitalismo: a de permitir a expulsão do
excedente da população que fornece o proletariado. As formas
dessa aliança foram várias, segundo as circunstâncias históricas.
[...] Seja qual for a forma dessa aliança, é paga pela extração de
uma fração da mais-valia em benefício da propriedade
fundiária. Pode-se agora falar de renda capitalista em sentido
pleno, já que é obtida da mais-valia. (AMIN; VERGOPOULOS,
1986, p. 24).

Considerando o trabalho como fundamento da condição de classe, que distingue os que vivem do trabalho dos que vivem por explorar trabalho, é possível vislumbrar aquilo que os aproxima daquilo que os separa. As classes proprietárias, seja de terra ou de quaisquer meios de produção, têm interesses

${ }^{8}$ Cf. Nota Técnica 17/2019. PFDC/MPF. 
manifestamente antagônicos aos daquelas que não os tem, porque as primeiras precisam controlar essa força vital e estas precisam se libertar do controle dessa força vital.

A classe acontece quando alguns homens, como resultado de experiências comuns (herdadas ou partilhadas), sentem e articulam a identidade de seus interesses entre si e contra outros homens cujos interesses diferem (e geralmente se opõem) dos seus. A experiência de classe é determinada, em grande medida, pelas relações de produção em que os homens nasceram ou entraram involuntariamente. (THOMPSON, 1987, p.10).

Certamente, a experiência assim caracterizada é insuficiente para instaurar o sentido do pertencimento, fator qualitativo mobilizador da identidade e da distinção no confronto interclasses, pois

A consciência de classe é a forma como essas experiências são tratadas em termos culturais: encarnadas em tradições, sistemas de valores, ideias e formas institucionais. (THOMPSON, 1987, p.10).

Ao se debruçarem sobre a formação do exército industrial de reserva no contexto da revolução industrial, Amin e Vergopoulos (1986) revelaram as sutilezas angulares da aliança entre burguesia e latifundiários, por mais que no plano imediato pudessem guerrear entre si.

Mesmo que a renda represente oneração aos capitalistas, forçados compulsoriamente a transferir para os proprietários fundiários uma parte da mais valia extraída dos trabalhadores a seu serviço, é justamente o interdito à terra que instaura a impossibilidade de as pessoas trabalharem com seus meios para si próprias, abrindo caminho para a exploração do trabalho.

\section{DES-ENVOLVIMENTO: FETICHE E TRUNFO DAS LUTAS DE CLASSE DO SÉCULO XXI}

Des-envolver é um verbo que expressa uma ação direta e oposta ao ato de envolver-se que, por sua vez, quer dizer unir. Evoca a barbárie como horizonte societário, se considerarmos a negação do sentido amplo do comprometimento mútuo e da solidariedade, princípios antagônicos ao laissez faire. (PORTO GONÇALVES, 2017) 
Partindo da premissa que todo conceito consiste em uma representação orientada para a ação, mister se faz compreender o des-envolvimento como jogo de palavras em sua expressão desnuda para problematizar o conceito sem hífen em sua ampla polissemia. Em um modo de produção onde a acumulação ampliada do capital é visceral, o desenvolvimento se expressa hegemonicamente como imperativo da transformação de bens naturais em mercadorias.

Ocorre que isso se dá por intermédio da única força criativa possível, o trabalho humano. Atualmente, além da redefinição dos termos negociais entre capital e trabalho, em prejuízo do último, a fragilização dos ecossistemas em escala planetária dá sinais evidentes de que já foram ultrapassados quase todos os limites para a auto regeneração. Certamente, os impactos são diversos tanto em qualidade quanto em densidade, pelo simples fato de resultarem do valor de troca inerente aos recursos existentes e sua mobilização segundo a posição geográfica e o respectivo lugar de quem o faz na divisão territorial do trabalho.

Mas poucos citadinos se dispõem a um esforço intelectual mínimo antes de digerir peças midiáticas e proclamas de tribuna que, salvo honrosas exceções, criminalizam os pobres do campo e vitimizam os poderosos no campo. Com isso, perdem a oportunidade de entender como a concentração fundiária afeta bem mais do que os sujeitos renegados.

Mais raros ainda são os que conseguem correlacionar concertação latifundista com crise ambiental, ainda que o fogo da floresta escureça o seu céu ${ }^{9}$ e o veneno invada seu estômago ${ }^{10}$. "Na verdade a questão agrária engole a todos e a tudo, quem sabe e quem não sabe, quem vê e quem não vê, quem quer e quem não quer. (MARTINS, 1994, p. 12-13).

Destruição dos biomas, extinção de espécimes da fauna e da flora são elementos dessa questão agrária de que nos fala o autor, cujas implicações desconhecem fronteiras espaciais e temporais. A rigor, não há acumulação sem privatização dos bônus e socialização dos ônus da apropriação da terra.

Eis o fermento da luta de classes. Da mesma maneira como a América Latina se convertera na fração do planeta mais adepta ao neoliberalismo, desde

9 No dia 19/o8/2019 diversos estados brasileiros e mesmo a cidade de São Paulo foram tomados pela escuridão por volta de 15:00 da tarde. O fenômeno se deu em virtude de uma combinação entre a fumaça proveniente dos incêndios florestais e o excesso de umidade do ar.

${ }^{10} \mathrm{Em} 10$ meses do governo Bolsonaro, 382 novos agrotóxicos foram liberados. 
a sua implantação no Chile, em 1973, nos albores do novo milênio aqui também brotariam amplas forças insurgentes, empurradas pelo legado de empobrecimento e marginalização social alhures, envoltos na premissa de que caberia ao mercado a tarefa de resgatar os povos do subdesenvolvimento, porque o Estado não se mostrara apto a fazê-lo.

Wolf (1976) ensina que a iminência do aniquilamento coletivo é o combustível das revoltas e revoluções. Nas últimas décadas do século passado, o malogro do desenvolvimento pela via das técnicas, e não da política, foi tomando corpo, tendo culminado no movimento antineoliberal, do qual poucos países escaparam, tornando-se regra desde o início do século XXI a saída de cena dos governos identificados com tal ordem. Situação essa que volta a se repetir, com revoltas populares em vários países latino-americanos ${ }^{11}$.

De acordo com a Comissão Econômica para a América Latina e o Caribe, no período de 2002 a 2014, dentre o conjunto da população latino americana, o número de pobres foi reduzido em aproximadamente $38 \%$ e o da pobreza extrema em mais de 30\%. Mas uma expressiva parte desse ganho social se perdeu em apenas 3 anos, pois em 2017 o número de pobres já havia subido quase $9 \%$ enquanto o número de pessoas em situação de pobreza extrema superava a casa de 30\% (CEPAL, 2019, p. 24). A evolução desse ciclo virtuoso fugaz, seguido pelo avanço do círculo vicioso, pode ser verificado na figura 4.

\footnotetext{
${ }^{11}$ Antes do final de 2019, três países já haviam revivido a experiência dos golpes de Estado (Bolívia, Brasil e Paraguai) e pelos oito enfrentavam explosivas manifestações populares com repressão violenta das forças públicas, a saber: Colômbia, Chile, Equador, Haiti, Honduras, Guatemala, Peru e Venezuela.
} 
Figura 4 - Índice de pobreza dentre a população latinoamericana (\%)
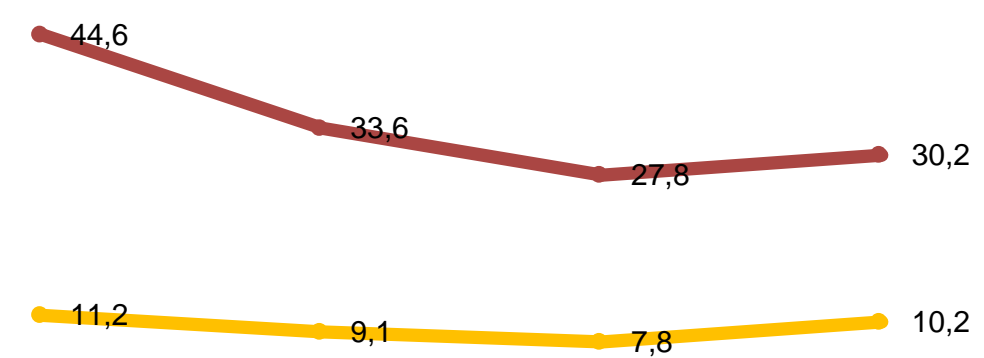

$\begin{array}{ccc}2008 & 2014 & 2017 \\ & \text { Pobreza } & \text { Pobreza extrema }\end{array}$

Fonte: CEPAL, 2019, p. 24.

Ocorre que dinheiro não some, apenas troca de bolso. De acordo com um relatório da consultoria de investimentos Credit Suisse Group, entre 2018 e 2019 o número de milionários ${ }^{12}$ aumentou 20\% no Brasil. No intervalo dos últimos nove anos, foi multiplicado por sete o número de pessoas nessa condição. A riqueza que explica a pobreza está no $1 \%$ da população mais rica que, em 2019, ficava com 49\% da riqueza nacional (CSG, 2019, p. 59).

Atualmente, poucos citadinos estão interessados em correlações entre invasão de terras, desmatamentos e queimadas com aprofundamento das desigualdades sociais. Mais cômodo é digerir peças midiáticas e proclamas de tribuna que, salvo honrosas exceções, criminalizam os pobres do campo e vitimizam os poderosos no campo.

Mais raros ainda são os que conseguem correlacionar concertação latifundista com crise urbana e crise ambiental, não obstante o fogo da floresta escureça o seu céu13 e o veneno invada seu estômago. "Na verdade a questão agrária engole a todos e a tudo, quem sabe e quem não sabe, quem vê e quem não vê, quem quer e quem não quer" (MARTINS, 1994, p. 12-13).

O ciclo dos governos progressistas que dominou a cena na América Latina nesse início de milênio reafirma a questão agrária tal qual nos fala o

12 Pessoas com renda superior a US\$ 1 milhão.

13 No dia 19/08/2019 diversos estados brasileiros e mesmo a cidade de São Paulo foram tomados pela escuridão por volta de 15:00 da tarde. O fenômeno se deu em virtude de uma combinação entre a fumaça proveniente dos incêndios florestais e o excesso de umidade do ar. 
autor, mas sob bases de um tempo aparentemente novo. O fato é que o ardil da inclusão pelo consumo compensatório em troca de reformas incômodas, não pode prescindir de uma escalada sem precedentes de açambarcamento dos bens ambientais. A rigor, não há acumulação sem privatização dos bônus e socialização dos ônus da apropriação monopolista da terra e o que nela há.

Sem a recomposição dos pactos de poder, a atenuação das duras condições de vida da maioria da população se deu nos marcos de uma nova geopolítica da velha subalternidade. Com base em uma mirada regional, Gudynas (2009) a define como nova forma de extrativismo, por combinar voracidade ambiental com progressismo social.

Para Delgado (2010), adentrou-se o milênio com um pacto de economia política onde a acumulação por intermédio da agricultura capitalista voltou a ser prioridade de Estado. O fomento ao mercado de terras, o fortalecimento das cadeias agroindustriais e do crédito rural canalizariam a extração do excedente econômico para o setor primário.

Em termos regionais, tal situação guarda mais semelhanças do que distinções, a julgar pela figura 5, em que optou-se pelo destaque aos países mais proeminentes, devidamente dispostos segundo a receita obtida com as exportações.

\section{Figura 5 - Bens primários no conjunto das exportações (\%)}

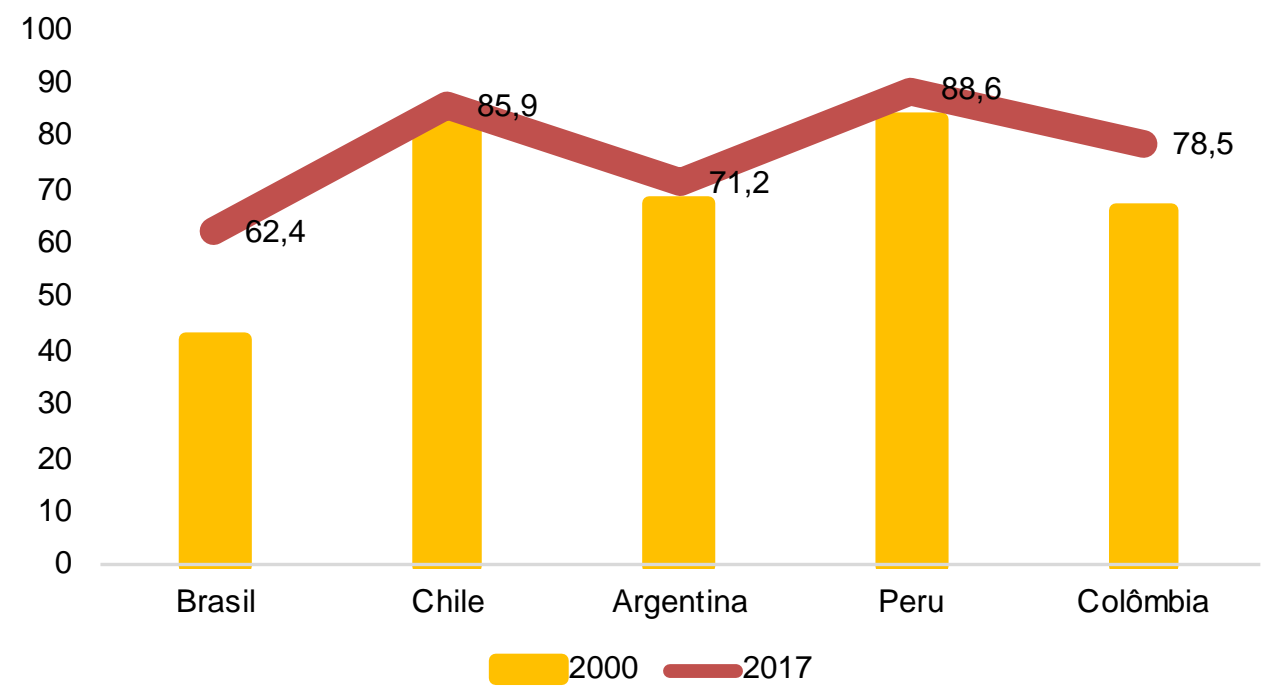

Fonte: CEPAL (2003; 2019). 
Verifica-se o quanto é frágil a ideologia do desenvolvimento como capilarização da riqueza e do bem estar. Inversamente, é a reprimarização da economia que se sobressai e o caso brasileiro é por demais elucidativo. Entre 1980 e 2000, a participação dos bens manufaturados nas exportações passou de 37,1 para 58\%, mas em 2017 já havia recuado para padrões muito próximos aos de 1980, mais precisamente a 37,6\% (CEPAL, 2003, p. 101; 2019, p. 41).

Segundo explica Delgado (2010), foi nesse contexto que a inserção externa se deu mediante a combinação entre a produtividade dos bens naturais e a captura da renda fundiária. Trata-se de um modelo onde a produção e a repartição do excedente econômico encerram armadilhas em duas dimensões: a produtiva, pois supõe superexploração do solo, subsolo, água, ar, enfim, dos bens disponíveis na biosfera, mas também na dimensão distributiva, pois impulsiona a concentração da riqueza.

A importância do fator terra no processo de acumulação ampliada se revela sobretudo quando são tomados dados de médio e longo prazo em qualquer escala que se queira analisar. A figura 6, a seguir, mostra a dinâmica de valorização dos ativos mais importantes do ponto de vista do mercado: ouro, ações e terras. O cálculo do mercado de ações deriva das 500 empresas mais proeminentes segundo o índice da Nasdac ou Bolsa de New York e o de terras reflete o preço médio nos EUA.

\section{Figura 6 - Valorização das terras agrícolas versus ações e títulos}

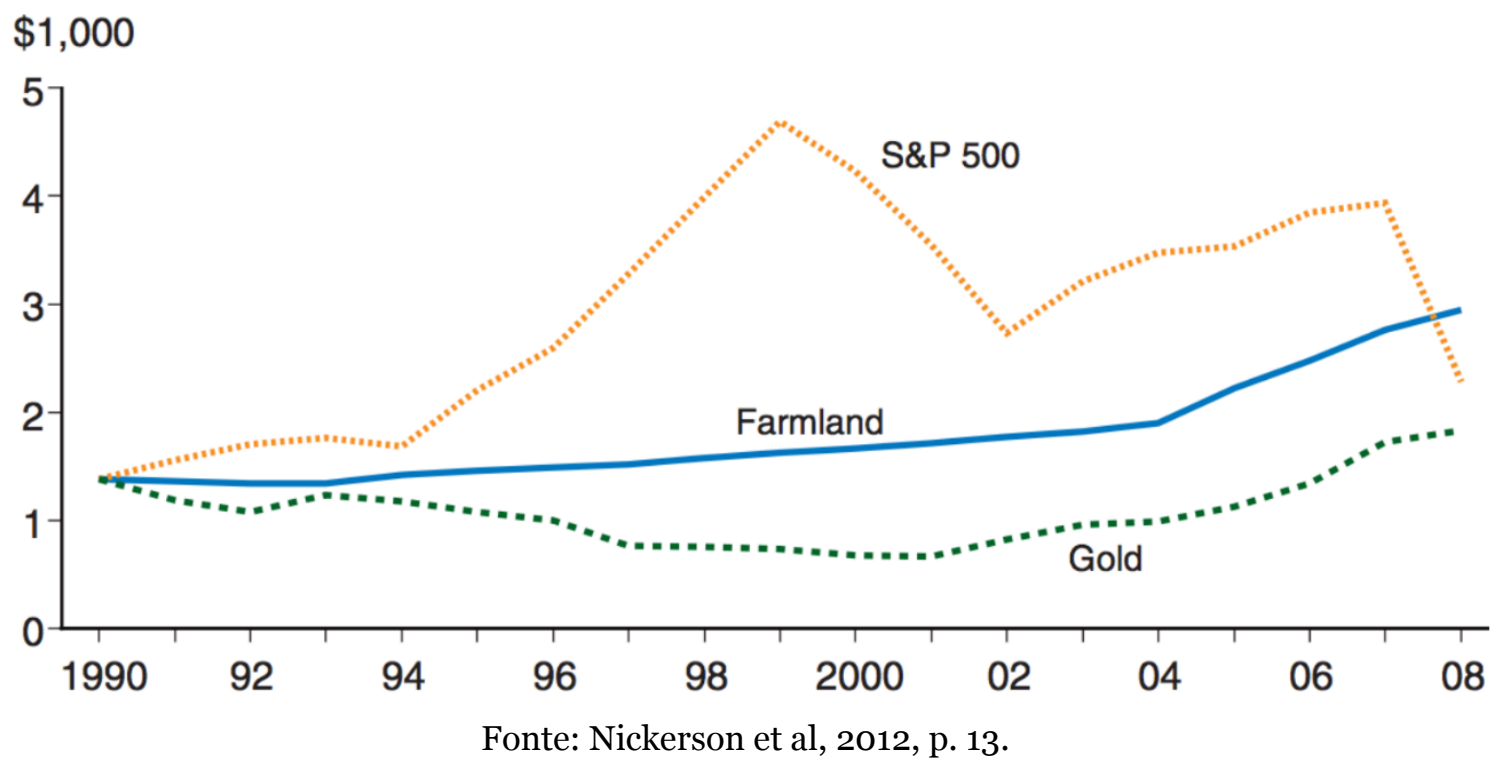


Verifica-se que mesmo as ações, que muitos creem ser a melhor opção de investimento, estruturalmente não rivalizam com a propriedade fundiária pela estabilidade e, conjunturalmente, pela rentabilidade. A razão é simples: terra é irreprodutível e, sob regimes de apropriação monopolista, é escassa.

Se isso se aplica ao Império, o que não dizer da Abya Ayala14, onde o despojo territorial é produto e indutor da geopolítica da subalternidade subsumida na produção de commodities agrícolas, mas também minerais que, igualmente, presume monopolização da superfície e dilapidação dos bens ambientais nela enraizado. Ativos e passivos territoriais são, portanto, o corolário de uma ordem onde a parcimônia raramente tem lugar.

Os ganhos de produtividade na fase expansiva das commodities viram renda da terra e do capital, capturadas privadamente pelos proprietários das terras, das jazidas e do capital; mas os custos sociais e ambientais da superexploração desses recursos e do trabalho precarizado aí envolvido são da sociedade como um todo. [...] Este quadro econômico de produção e repartição do excedente econômico não se compraz com democracia política e social. (DELGADO, 2010, p. 123).

Em outras palavras, a concentração fundiária expressa uma aliança de classes que tolhe a liberdade difusa, o princípio basilar da ordem burguesa contido no ordenamento jurídico do Estado de Direito. Sua consistência evoca legislações disciplinadoras do uso do solo, de modo a impedir que os proprietários possam dispor livremente dos bens agregados à terra por obra da natureza.

Nesse sentido, a terra urbana é mercadoria tornada escassa pela mesma lógica monopolista que fustiga o campo, sendo que a acessibilidade à moradia não se efetiva pelo critério do direito fundamental da pessoa humana. A relação entre campo e cidade é, assim, mais estreita do que fazem crer os adeptos da dualidade, pois quanto maior a fatia de terra agricultável imobilizada como reserva patrimonial ou utilizada como reserva de valor, maior o nível de marginalização nas cidades.

Ao interditar a permanência dos não proprietários no campo, o latifúndio transmuta violências, primariamente expressas em morticínio nas cidades. De acordo com o Escritório das Nações Unidas sobre Drogas e Crime (UNODC,

${ }_{14}$ Abya Yala é a América, segundo a tradição indígena. 
2019, p. 13), a taxa de homicídios está diminuindo no mundo, com exceção da América, onde está aumentando sistematicamente.

Com apenas $13 \%$ da população mundial, foram registrados $37 \%$ dos assassinatos ocorridos em 2017. No Brasil, a taxa de homicídios é cinco vezes superior à média mundial, sendo o país com o maior número de homicídios do planeta. Somente em 2017, foram assassinadas 65.602 pessoas, a maioria homens negros jovens, segmento mais exposto à violência associada à marginalização.

Essa situação desafia soluções fáceis, contudo a promessa da mudança das leis para permitir a disseminação das armas de fogo acabou por se tornar um fator decisivo para a eleição que levou Jair Bolsonaro à presidência do Brasil. No latifúndio foi ancorada a aliança que o elegeu e é para o latifúndio que até esse momento parte expressiva das atenções do governo se voltam.

Situação paradoxal, considerando os que foram seduzidos por um pretenso pertencimento de classe, mas que seguem prisioneiros da condição de classe que a origem (e a quantia) dos seus rendimentos determina. Nenhuma interdição ou acessibilidade, pela via das armas ou das redes, poderá blindá-los dos passivos do latifúndio. Além da violência difusa, há as vulnerabilidades econômicas e ambientais que, mesmo desigualmente distribuídas, desobedecem às fronteiras.

\section{CONSIDERAÇÕES FINAIS}

Dizia Galeano (1994) que, na América Latina, são as próprias sentinelas quem abrem a porta aos invasores. Atualmente, isso não poderia ser mais evidente: a implosão das estratégias de cooperação regional, a exemplo da UNASUL e mesmo do Mercosul, explica-se pela rendição à geopolítica imperialista que arranca qualquer arremedo de soberania e altivez.

Não que os governos de centro esquerda tenham privilegiado métodos antagônicos. A própria definição - progressistas - os denuncia. Eles foram reféns do ideário do desenvolvimento como processo civilizatório da modernidade colonial.

Ainda que tenham sido legítimos os propósitos de alguns deles, ou alguns propósitos de todos os que de alguma maneira se colocaram em luta por 
sociedades mais igualitárias, os malogros históricos não estão entre as lições aprendidas na contemporânea Abya Yala. A incompreensão sobre a centralidade da terra na (u)topia da liberdade é por demais severa aos marxistas convictos de que o motor da história está na contradição entre capital e trabalho.

Aliás, o expurgo do fator renda da terra como na presunção de que os sujeitos da agricultura parcelar - os camponeses, bem como os dos territórios originários ou tradicionais - os indígenas, quilombolas etc. são residuais, incapazes de pautar e disputar um projeto próprio de enfrentamento ao capital.

Feito reféns da visão do protagonismo proletário na luta de classes, pela própria experiência de classe que lhes é inerente, vislumbram a exploração perpetrada pelos capitalistas, mas são incapazes de confrontar a lógica da mercadoria, porque essa lhes será constitutiva enquanto estiverem fadados a vender a força de trabalho.

Nesses termos, há uma diferença do comércio, que é estruturante, ao do circuito das trocas. Como ensina Polanyi (1980), estas existem desde a idade da pedra, mas tem como princípios reguladores a domesticidade, a reciprocidade e a redistribuição. O modelo neoextrativista contraria tudo isso, é antagônico à lógica dos sujeitos do circuito simples de mercadorias. Porém, foi estrategicamente utilizado pelos governos que viram na superexploração da natureza uma forma rápida e fácil, politicamente, de obter a fração adicional de dividendos para aliviar a pobreza sem tocar, ou melhor, fazendo crescer a riqueza dos ricos.

O fato é que isso se fez em prejuízo dos ativos territoriais, aqui entendidos como estruturas sociais e bens ambientais articulados dentro de uma dinâmica virtuosa, onde a conservação ativa de tudo o que se traduz em bem-estar, se sobressai. Liberdade e integridade ética e estética são partes desse corolário.

Desafortunadamente, o desenvolvimento idealizado e em curso no momento é profuso em passivos territoriais. Estes resultam da falta de parcimônia na apropriação de frações da superfície sobre as quais estão todos os vínculos da biosfera, provocando dinâmicas viciosas traduzidas em concentração da riqueza com aprofundamento dos estéreis ambientes da pobreza. 
Seu livre curso requer ações preventivas contra todas as possibilidades de insurgência. Para isso, o Estado classista ressuscita a "defesa da pátria", colocando os tanques e fuzis nas ruas para permitir que a floresta arda, o solo morra, a água enegreça e os corpos se esgotem.

A luta de classes atrai as predisposições para o ódio ressentido e colore mentes e terras de vermelho, situação que deverá se acentuar com o novo ciclo de despojo contra os trabalhadores da cidade e contra os sujeitos do campo. Avançam com as forças constituídas sob a batuta dos ultraneoliberais de caserna e de botequim.

A bola da vez são os direitos aos mínimos vitais, para o banquete farto da mais valia. Simultaneamente, as terras e territórios de vida vão sendo preparados para a metamorfose em campos privados para mineração, para produção de comida pouca e, fundamentalmente, para colheita da renda absoluta da terra.

Inquietante tempo obscuro, que mobiliza usurpadores e usurpados para lutarem pela usurpação dos direitos e garantias fundamentais da pessoa humana e do bem comum. Intenso tempo insurgente, que mobiliza gentes nas conflagrações populares em tantos cantos dessa América Latina mais uma vez conflagrada. Prescrevente tempo do desenvolvimento como liberdade, política para alguns, de mercado para outros.

Não vale antecipar desfechos, a pertinência de seguir em frente o desaconselha. Cabe cultivar a paciência histórica, essa disposição que pede enlaces e resiliência para construir na (a)diversidade, antes que o devir se perca na história como farsa.

Eles passam. E nós estamos e persistimos em estar aí, de mãos abertas e de punho erguido, ano após ano, década após década, geração após geração!

Estamos aqui! Estamos por toda a parte.

E estamos juntas e juntos uma vez mais. 


\section{REFERÊNCIAS}

AMIN, S.; VERGOPOULOS, K. A questão agrária e o capitalismo. 2. ed. São Paulo: Paz e Terra, 1986.

BRANDÃO, C.R. Sobre a Esperança. Mensagem para encerrar 2016 e esperar um "Ano Novo". In: Portal das Comunidades Eclesiais de Base. Disponível em: http://portaldascebs.org.br/2016/12/o5/sobre-a-esperanca. Acesso em: 18 ago. 2019.

CEPAL. Comisión Económica para América Latina y el Caribe. Anuario estadístico de América Latina y el Caribe 2002. Chile: CEPAL, 2003.

CEPAL. Comisión Económica para América Latina y el Caribe. Anuario Estadístico de América Latina y el Caribe 2018. Santiago de Chile: CEPAL, 2019.

CORREA, R.L. Análise crítica de textos. GeoUERJ, Rio de Janeiro, n. 14, p. 7-18, 2. sem. 2003.

CORTINA, A. Aporofobia, el rechazo al pobre: un desafío para la democracia. Barcelona: Paidós, 2017.

CSG. Credit Suisse Group AG. Global Wealth Report 2019. USA: Credit Suisse Securities, 2019.

DELGADO, G.C. Especialização primária como limite ao desenvolvimento. Desenvolvimento em Debate, v.1, n.2, p.111-125, jan. - ago. 2010.

GALEANO, E. As veias abertas da América Latina. 36. ed. Rio de Janeiro: Paz e Terra, 1994.

GOVERNO libera 57 novos agrotóxicos; total no ano chega a 382. Jornal o Globo. Caderno Sociedade, 02 out. 20129. Disponível em: https://oglobo.globo.com/sociedade/governo-libera-57-novos-agrotoxicostotal-no-ano-chega-382-23992542. Acesso em: 03 out. 2019.

GUDYNAS, E. Diez tesis urgentes sobre el nuevo extractivismo.

Extractivismo, política y sociedade, Quito, p. 187-225, 2009.

IBGE. Instituto Brasileiro de Geografia e Estatística. Censos Agropecuários 2006 e 2017. Sistema IBGE de Recuperação Automática. Banco de Dados Agregados. Disponível em: http://sidra.ibge.gov.br. Acesso em ago. 2019.

INCRA 2014. Instituto Brasileiro de Colonização e Reforma Agrária. Sistema Nacional de Cadastro Rural: estatísticas cadastrais situação jurídica em 2014. Banco de dados.

INCRA 2019. Instituto Brasileiro de Colonização e Reforma Agrária. Sistema Nacional de Cadastro Rural: dados sobre estrutura fundiária do Brasil - 
Julho de 2018. Disponível em: http://www.incra.gov.br/consulta-imoveisrurais. Acesso em: 11 nov. 2019.

INPE. Instituto Nacional de Pesquisas Espaciais. A estimativa da taxa de desmatamento por corte raso para a Amazônia Legal em 2019 é de 9.762 km². Disponível em: http://www.inpe.br/noticias/noticia.php?Cod_Noticia=5294. Acesso em: 18 nov. 2019.

MARTINS, J.S. A política do Brasil. São Paulo: Contexto, 2011.

MARTINS, J.S. O poder do atraso. São Paulo: Contexto, 1994.

MARX, K. O capital. Rio de Janeiro: Civilização Brasileira, 1974. Livro 3, Volume 6.

MPF. Procuradoria Federal dos Direitos do Cidadão. Nota Técnica 17/2019. Brasília: PFDC/MPF, 4 out. 2019. Disponível em: http://pfdc.pgr.mpf.mp.br/at uacao-e-conteudos-de-apoio/notas-tecnicas/nota-tecnica-no-17-2019-pfdc-mpf. Acesso em: 22 out. 2019.

NICKERSON, C. et al. Trends in U.S. farmland values and ownership. EIB-92. U.S. Dept. of Agriculture, Econ. Res. Serv, U.S. Department of Agriculture, Nebraska, p. 1-48, feb. 2012.

OXFAM. Unearthed: land, power and inequality in Latin America. EUA: OXFAM, 2016.

PAULINO, E.T. Dos preceitos constitucionais democráticos ao império do latifúndio na gestão fundiária. In: CAMACHO, R; COELHO, F. O campo no Brasil contemporâneo. Curitiba: CRV, 2017. p. 135-160.

PEC 80/2019. Altera os artigos 182 e 186 da Constituição Federal para dispor sobre a função social da propriedade urbana e rural. Brasília: Senado Federal, 2019. Em tramitação.

POLANYI, K. A grande transformação: as origens da nossa época. Rio de Janeiro: Campus, 1980.

PORTO GONÇALVES, C.W. De utopias e de topoi: espaço e poder em questão. Geographia Opportuno Tempori, Londrina, v. 3, n. 2, p. 10-58, 2017.

SPAROVEK, G. et al. Nota técnica preliminar sobre o anúncio de Medida Provisória de regularização fundiária autodeclarada. Geolab: ESALQ/USP, 17 out. 2019. Disponível em: http://www.imaflora.org/downloads /biblioteca/5da9d4efo2ea7_NT_MP_fundiaria_outubro2019final.pdf. Acesso em: 23 out. 2019.

THOMPSON, E.P. A formação da classe operária inglesa. 3. ed. Rio de Janeiro: Paz e Terra, 1997. 3 v. 
UNODC. Global Study on Homicide 2019. Vienna: UNODC, 2019

WOLF, Eric R. Las luchas campesinas del siglo XX. 4. ed. México: Siglo

Veinteuno, 1976.

Recebido em maio de 2019

Aceito em junho de 2019 